Marquette University

e-Publications@Marquette

Economics Faculty Research and Publications

Economics, Department of

$1-1-2001$

\title{
Agent Identity in Economics
}

John B. Davis

Marquette University, john.davis@marquette.edu

Published version. "Agent Identity in Economics," in The Economic World View: Studies in the Ontology of Economics. Eds.Uskali Mäki. Cambridge, NY: Cambridge University Press, 2001: 114-131. Publisher Link. (c) 2001 Cambridge University Press. Used with permission. 


\section{$7 \quad$ Agent identity in economics}

JOHN B. DAVIS*

\section{Introduction}

Many economists would agree that as a social science economics aims to explain cause-and-effect relationships in economic life, and aims to do so in close conjunction with an analysis of agency. Yet though economists constantly refer to economic agents when they speak of individuals making choices, the concept of agency itself is not sharply defined in economics. I define agency as the power to initiate and bring about events. Economic agents, then, have the power to initiate economic activity, and, together with other causal factors, such as capital, institutional arrangements, natural resources, etc., help bring about events seen as the causal effects of their actions. Choice, economists' main concern, is thus an aspect of agency in that its analysis helps us account for how economic agents act on the world. But choice needs to be understood in a wider framework of cause-and-effect explanation if economic agents are to be understood specifically as agents with powers to initiate and bring about events when making choices.

Another way of seeing economic agents as agents in a causal sense is to recognize that on this conception economic agents actually exist, and that adopting a cause-and-effect view of economic agents commits one to an ontological realism about economic agents in the sense distinguished by Mäki in his taxonomy of realisms (1992). Note that while most economists would say they are interested in actually existing economic agents, many would also allow that the logic of choice - or how agents ought to behave - may be evaluated apart from the question of whether there are agents whose choice behavior that logic describes (Sugden 1991,

* Thanks to Tony Lawson, Uskali Mäki, Jochen Runde, and Alex Viskovatoff - without implication - for thoughtful comments on an earlier version of this paper. 
p. 752). On the view here, however, the investigation of economic agency requires one to suppose that there are economic agents with real powers to bring about events as the effects of their actions. This emphasis calls for some re-orientation of contemporary economics, since with the considerable development of axiomatic decision theory in the postwar period pursued apart from a realism about economic agents, it seems fair to say that the discipline has not focused on explaining how economic agents actually bring about events.

In the discussion that follows I begin to set out an ontological framework for an analysis of economic agents by developing stategies for investigating the location and scope of economic agency, where each of these considerations pertains to a relatively separate set of issues involved in an ontology of agents. A related way of approaching the topic of agency that has tangencies to philosophers' work on personal identity is as the investigation of the identification of economic agents or agent identity in economics. This paper consequently might also be thought to investigate how we identify or account for the identity of economic agents in terms of the location and the scope of their agency. Or, using philosophers' personal identity language, the paper investigates both how we distinguish or individuate agents - the business of locating them - and how we re-identify or track agents through change in their characteristics and surroundings - the business of determining what scope their agency possesses or sustains.

The rationale for using philosophers' thinking about personal identity to investigate agent identity in economics needs to be highlighted at the outset. In supposing economic agents actually exist, one in effect assigns oneself the task of explaining how and for how long economic agents exist. How they exist is a matter of accounting for where they are active. I label this the question of agents' location, though it will be readily seen that more is involved than simply picking out agents' site of operation, since where they are active leads us immediately to claims about the manner in which they are active and some ascription of powers to them. The question of how long agents exist concerns the durability of their powers. I label this the question of the scope of economic agency. Thus described, it will be seen that the issues of location and scope of agency are means of explaining agents' causal effectiveness. This focus is slightly different than is involved in philosophers' investigation of personal identity, since only some approaches to personal identity emphasize the effects of individuals' actions on the world. But the agent identity approach adopted in this paper shares the general realist concern personal identity theorists have regarding the persistence and distinctness of a type of real being in the world. For this reason, personal identity 
theory offers insights for economics that may help develop an ontologically realist view of economic agents as having causal powers.

Mäki, in his taxonomy of realisms, distinguishes referential realism and representational realism. Referential realism, or the semantical thesis that the terms of language and science refer to real entities, connects in important respects to the issue of how we locate economic agents. Our use of language reflects our ontological commitments, and one such commitment is that the things we refer to are real entities. But to successfully refer to real entities implies that we can ontologically distinguish or individuate those real entities in the world. Thus we may begin to investigate the location of agents through an analysis of our modes of reference. In contrast, representational realism, or the semantical thesis that attributive statements ascribe properties to real entities, has important connections to the issue of what scope or extent of power economic agents may be said to have. Here our ontological commitments specifically concern the magnitude and duration of economic agency, or how long and with what force real agents exercise their powers as agents. Thus we may begin to investigate the scope of agency through an analysis of how economic agents are represented in the language of economic theory.

This paper consequently attempts an analysis of the location and scope of economic agency in terms of these two forms of realism, so as to link ontological and semantical thinking on the subject. It postpones a veristic realist analysis of agents (also distinguished by Mäki) on the grounds that establishing truths about the forms of economic agency first requires that one identify those agents whose actions have real effects in economic life. Roughly speaking, ontology precedes epistemology. As an illustrative framework, the second section of the paper begins by critically examining the standard neoclassical view of economic agents, and characterizes it as unsuccessful in its ability to identify economic agents. The third section of the paper then offers an alternative, realist approach to locating economic agents, discusses routines as a form of phenomena that exhibits agency relationships, and closes with a proposed criterion for locating agents. The fourth section turns to how we may address the difficult topic of agency's scope, considers the point-in-time and throughtime dimensions this involves, and introduces considerations pertaining to multiple sources of agency and changes in its structure. The paper concludes with three brief remarks to clarify principal themes of the discussion. 


\section{The neoclassical approach to locating economic agents}

As an ontological issue, the location of agency concerns how we distinguish or pick out agents in economic life. To appreciate the nature of the issue, it is worth noting at the outset that this aspect of the topic of agent identity is less central to philosophers who investigate personal identity. When philosophers analyze the conditions under which individuals maintain their personal identities, they generally suppose that they know whose identity is at issue (namely, that of individual human beings), and thus rarely stop to worry about where agency is located (and whether individual human beings are indeed agents). For example, in Parfit's (1984) famous teletransporter examples regarding personal survival, he imagines what might happen to himself were his own body dematerialized and reconstituted elsewhere under various scenarios. Most economists also tend to assume that locating agents is not an issue, since they believe that individuals are automatically agents. Even when economists concern themselves with situations in which people make choices for others, mobilize others' resources, and act as others' agents, that is, in principal-agent situations, they assume there is no difficulty in locating agency, since delegated authority stems from choices previously made by autonomous individuals who are agents. But it seems fair to say that without an account of what makes an individual an independent agent in the first place - one in whom the power to affect the world exists - it is question-begging to say that individuals are even in a position to delegate authority and assign decision-making responsibility to others. Unlike philosophers in their treatment of personal identity, then, economists cannot avoid first confronting the problem of how we locate causally efficacious agents preparatory to a full analysis of the scope and extent of their powers as distinguishable agents.

Note first, then, that when we use language to refer to things, we suppose that we can locate and distinguish the things we refer to. If one uses the term "chair" referentially, this implies one can pick out an object thought to be a chair, and distinguish it from other pieces of furniture. This suggests we ought to look at how economic theories make reference to the things they name. But before doing so, we ought to first ask ourselves what conception of reference a theory involves, since it is well possible a theory employs a view of reference that does not help us to pick out the sorts of things we are interested in ontologically identifying. For example, it might be my theory of reference that "whatever my friends call a 'dog' does indeed pick out real dogs in the world," where that they also refer to people they dislike as dogs tells us that my theory 
of reference does not enable me to consistently pick out real dogs. Of course these friends do refer when they use the term "dog," but because their use of the term is often metaphorical, they do not thereby help us to disinguish and locate real dogs. Here my theory of reference is inappropriate to the task at hand. And since our project here is not to investigate the rhetorical use of language, but to pursue the ontological project behind referential realism, we ought similarly to ask whether our economic theories employ theories of reference that will allow us to locate and distinguish real economic agents.

Let us distinguish two philosophical approaches to reference for constative utterances, the early analytic Fregean theory dating from the turn of the century (Frege 1892; Russell 1905), and the more recent causal theory associated with scientific realism (Kripke 1971; Putnam 1970, 1973). The Fregean theory explains the meaning of a name (common noun or proper name) in terms of its intention, or in terms of that conjunction of properties analytically true of the name. As Putnam characterizes it,

On the traditional view, the meaning of say, "lemon," is given by specifying a conjunction of properties. For each of these properties, the statement "lemons have the property P" is an analytic truth; and if $\mathrm{P} 1, \mathrm{P} 2, \ldots, \mathrm{Pn}$ are all of the properties in the conjunction, then "anything with all of the properties $\mathrm{P} 1, \ldots$, $\mathrm{Pn}$ is a lemon" is likewise an analytic truth. $(1970$, p. 51$)$

The theory then supposes that the intension of a name determines its extension, where a name's extension is that to which it refers - or more simply that meaning determines reference. The theory is neo-Kantian in that the logical structure of language (rather than as for Kant the psychological structure of the mind) determines what can be picked out and said about things in the world. But this is problematic, since it essentially renders the idea of a world independent of thought empty (as Kant did the notion of things-in-themselves), creates ambiguities between the act of judging and that which is judged, and generates paradoxes of meaning variance across conceptual structures à la Kuhn.

On the causal theory, in contrast, it is argued that names come to refer in a quite different manner. Things are, as it were, "baptized" at some historical point in time, and then generally retain their original names through causal chains of events linking the inaugural naming to later language-users, despite modifications in meaning and the way names are understood. On this theory reference is accounted for in terms of our causal interactions with things in the world and among us, and presupposes that we can ontologically distinguish real entities from one another. Unlike the neo-Kantian approach, that is, things in the world are first 
supposed to be distinguishable and re-identifiable through change, and this conditions the way in which we use language to refer to them. Put differently, reference is not established in an a priori manner by picking out things to which definitions should apply, but rather in an a posteriori manner by affixing names to the things we distinguish.

In Davis (1989), I argued that neoclassical economic theory in its axiomatic form employs a Fregean approach to reference, and that, because the Fregean approach does not provide an adequate account of reference, axiomatic neoclassical economic theory thereby fails to distinguish and pick out real economic agents in the world. Neoclassical economic theory relies on the Fregean theory of reference, essentially because it distinguishes and defines distinct economic agents in terms their different preference sets. Of course it is not analytically true that particular individuals have the particular preferences they do, but it is analytically true that any given individual is defined in terms of his or her own preferences. Our language sometimes obscures this point, because it allows us to say two individuals may "have" the same preferences. However, the theory clearly holds that two individuals may not have the same preferences in the sense of one doing the other's preferring. Preferring, as a propositional attitude, always implicates the particular individual doing the preferring, and is thus inseparable from that individual. Understood in this way, the theory holds that distinguishing two individuals is analytically equivalent to distinguishing two sets of own preferences.

How, then, does reference actually fail on this view? In Davis (1995), I argued that using an individual's own preferences to distinguish that individual presupposes the very individual those preferences are meant to distinguish. If a set of preferences picks out an individual, they must be that individual's preferences and not someone else's preferences. But if we have already picked out the individual to whom a set of preferences belongs in order to call these preferences that individual's own preferences, we cannot then use those preferences to pick out that individual. ${ }^{1}$ Neoclassical theory thus involves itself in a circularity in its implicit account of individual and agent identity, arguably causing it to employ the ad hoc assumption that preferences are exogenous to foreclose critical evaluation of its individualist project. For our purposes, however, the conclusion that is of chief interest here is that the theory is unable to

1 An early antecedent to this argument is Bishop Butler's charge that Locke's view, that individual identity depends on memory and states of consciousness, was circular. Butler argued that memory presupposes rather than explains personal identity. Hume, whose critique of the idea of the self is better known, essentially followed Butler in this argument (see Noonan 1989). 
locate real economic agents in the world. Its claim that individuals are agents, that is, is not supported by an understanding of reference that gives us a means of actually distinguishing individuals as real economic agents.

It thus follows that neoclassical theory lacks a way of systematically distinguishing between agents who are single individuals and agents made up of groups of individuals. Gary Becker's family decision-making analysis is a good example (1976). Husbands' preferences are taken to represent wives' and other family members' preferences, thus substituting the preferences of a single individual for a group of individuals. But because own preferences cannot pick out individuals, this account cannot distinguish (as feminists have continually argued) the case of a husband acting on his own preferences in the name of the family from the case of a husband acting on some sort of truly shared family preferences. Subsequent intra-family bargaining models have attempted to get around Becker's difficulty by assuming that husbands and wives are both independent agents whose negotiations create shared preferences for the family as a joint agent. But this similarly begs the question of whether husbands and wives are independent agents in the first place. In comparison to Becker's analysis that cannot determine whether husbands are single agents or representatives of group agents, the bargaining approach cannot determine whether individual agents constitute a group agent or a pre-existing group agent enfranchises individual agents.

But that neoclassical theory cannot credibly distinguish between agents who are single individuals and agents made up of groups of individuals, implies that it fails to locate agency in the world. And, failing in this first step, it cannot proceed to investigate the issues surrounding determination of the scope of agency, where that concerns the duration and magnitude with which distinguishable economic agents exercise their powers. Indeed in Davis (1995), it was also argued that even were we to suppose individuals are distinguishable economic agents (or locate agency in individuals), neoclassicism's dynamical analysis of human capital accumulation precludes its re-identifying them as distinct agents through change. Specifically, since on time allocation models (Becker 1965) certain of an individual's preferences are enhanced in significance by past accumulations of human capital, human capital accumulations indirectly contribute to the constitution of an individual's identity over time. But that we accumulate particular human capital stocks is partly a function of the price system and thus the decisions and preferences of others. This indirect influence of other individuals' preferences on any given individual disrupts neoclassicism's attempt to distinguish individuals in terms of their own preferences, making their re-identification 
through change problematic. And lacking an ability to track individuals through change, the theory has few resources to explain the scope of agency in terms of its magnitude and duration.

What this discussion of neoclassical theory is meant to demonstrate is that addressing the problems involved in explaining agency requires that a theory be formulated so as to take ontological commitments seriously. One cannot, then, simply assume individuals are always and everywhere agents, because one's ideological predilections encourage one to think this must be the case. Rather, given this intellectual predisposition, one needs to establish when and how individuals are able to act as agents. Neoclassical theory, to be fair, is hardly alone in its limited success in this regard, since similar sorts of arguments could be developed to show how methodologically collectivist theories fail to refer to distinguishable and re-identifiable group economic agents. In the section that follows an attempt is made to describe how one might go about locating economic agents through an analysis that places ontological realism in the foreground.

\section{A realist approach to locating economic agents}

How should we proceed if our first task is to explain how economic agents are distinguished from one another? The circularity problem associated with the Fregean approach to reference arises when one attempts to distinguish agents using an a priori, definitional criterion, primarily motivated by theoretical concerns (as the neoclassical preference criterion is motivated by the desire to apply the theory of instrumental rationality to all economic agents). Suppose, however, one were rather to attempt distinguishing economic agents in an a posteriori manner where this involved making explicit use of the causal theory of reference. In this instance, theory is built up around an inherited set of ontological commitments, namely, that such-and-such sorts of things exist in the world, which we are able to refer to by developing our theories around past namings (or "baptisms") meant to pick out and distinguish these real entities. Theory from this perspective follows rather than precedes reference, and accordingly allows different theories to share objects of reference, and so avoid the problem of meaning variance.

It will naturally be said in response to this suggestion that premising a set of ontological commitments itself involves some theory, and that it is illusory to think one can postpone theorization until one has agreed on 
what one is referring to. This is certainly correct in that there is indeed a theorization implicit in one's ontological claims, but I will put this difficulty aside here by assuming that the sort of implicit theorizing we imagine attaches to many of our ontological commitments is extratheoretical in the sense of not belonging to any particular theory developed by an identifiable collection of professional theorists. Different economic theories, for example, can refer to "markets" as real entities, but in doing so they adopt a very basic conception not reducible to any one group's theorization of markets. Specifically, markets involve exchange, the items exchanged are valued, traders in markets have different interests, some form of property relationship is implied, etc. Loosely, we might say that rather than presuppose implicit theorizations, the use of terms such as "markets" signals widely held beliefs we may understand as constituting collections of "social facts." Following Gilbert (1989) we may characterize social facts as facts in the eyes of reasonably informed individuals in society, where their ordinary understanding of these facts contributes a conceptual element separate from the further interpretative contribution that comes of more systematic analysis in social science theory. The prior element of understanding contributed by society both underlies social facts' status and acceptance as facts in society, and serves as a conceptual penumbra about these facts that assists their further analysis in more formal social science investigation. An a posteriori social science approach, then, attempts to anchor investigation in what the social world takes as given, rather than in a series of deductions made from theories constructed around views of a subject matter's essential requirements. $^{2}$

From this perspective, we may suppose, first, that analysis of the set of social facts relevant to agency begins with attention to evidence regarding how economic agents themselves understand the distribution and scope of agency in the economy. Presumably agents of any sort must rely on some understanding of agency in order to act as agents. Here the causal theory of reference comes into play in that an acknowledged set of social facts would naturally include facts about how historically we have come to pick out and refer to agents. On the causal theory, reference depends on historical namings or "baptisms" and subsequent chains of connection as names evolve, change, and are modified. Economic agents, then, rely on this information in acting as agents just as they rely on various other ordinary social facts.

Second, our investigation of those social facts relevant to agency

2 The approach here also distances itself from the traditional empiricist project of beginning with scientists' collections of observation statements. 
requires we also recognize that, because economics in its mission as causal social science aims to characterize economic life in terms of relatively enduring relationships, the evidence regarding agency relevant to our interests in economics concerns what we may observe in persistent patterns of economic activity. Clearly we do not expect to learn much about agency from evidence about episodic phenomena. These two points together imply that the social facts which underlie an analysis of agency in economics are those recognized by the economy's agents in connection with recurring patterns of activity investigated in science. It seems uncontroversial to add, thirdly, that these recurring patterns of activity involve intentional behavior in situations of social interaction. Intentional behavior, of course, is our principal concern in investigating economic agency, while social interaction allows our scope to include relations between individual agents, between group agents, and between individual and group agents.

Following the lead of Nelson and Winter (1982), then, I propose that these relatively enduring patterns economists wish to investigate be initially described as routines or as routinized behavior. I define routines in economic life and elsewhere as organized collections of rules and procedures that guide behavior in regularly encountered circumstances. Routines help individuals recognize domains of activity in which they may act. Routines do not themselves have causal powers, but rather create a framework in social settings that permits the assignment of agency to individuals who act. ${ }^{3}$ Central in this regard is the normative force possesed by the rules and conventions that make up routines. Rules and conventions tell us what we ought to do when we participate in a given routine. Thus an individual who abides by a routine becomes an agent in accepting the normative force of the rules and conventions characteristic of that routine. ${ }^{4}$

Other units of social analysis might be proposed, but there are important advantages to focusing on routines in an analysis of agency. First, since routines may be investigated for both individuals and groups, an examination of routines per se is not likely to bias our analysis at the outset toward either individualist or collectivist interpretations of the location of agency. Indeed both individual and group responsibilities are often recognizable in the duties that many routines imply. Second, because routines tend to be relatively self-contained social practices, they

${ }^{3}$ Obviously some routines are personal and carried out mostly apart from other individuals. The discussion here focuses on those routines that involve social interaction.

${ }^{4}$ I do not wish to suggest that agency does not exist outside of the context of routines. Routines, however, provide a valuable framework in which agency may be explained in economic life. 
appear more susceptible to analysis than many other more complex forms of behavior. More complex behavioral settings can indeed plausibly be argued to combine routines, so that these "institutional" environments are explained in terms of routines as their elements. Third, routines are an ordinary feature of the social world, and as such their common-sense description does not require immediate introduction of elaborate theoretical constructs. In fact, almost anyone can both describe a variety of routines in which people engage, and on prompting cite a number of facts relevant to the scope and location of agency that these routines imply.

For example, in economic life, say in the context of business firm routines, many can describe routines employees regularly observe, and analyze this evidence to produce an initial set of facts regarding the location of agency in business firms. What sôrt of analysis we initially attempt of course depends upon what cause-and-effect questions immediately concern us. Suppose we are interested in how a firm's organization causes it to address new business, and we find that a firm's routine is that customer orders to purchase goods are sent sequentially to the billing and shipping departments. That the group agent made up of the shipping department does not act before the group agent made up of the billing department locates agency at different points and different times in the firm with respect to new orders. If we also learn that departmental subroutines require that new business be processed by teams of individuals in each department, we might further conclude that agency rests with departments rather than individuals. Alternatively, if in each department the routine adopted requires that the first available individual take sole responsibility for new business until it is concluded, we might say that individuals act as agents, but that their agency is rotating and recurrent, rather than continuous, where this is a matter of numbers of individuals in a department, volume of business, time needed per order, etc. Or, a department might include a routine for trouble-shooting unexpected problems that is always delegated to the same individual. This sort of case clearly would contrast with the revolving responsibility type of routine in which individuals act in the name of their department.

Note that these simple examples treat routines as if they were isolated from one another. However, routines clearly occupy places in larger patterns of behavior and/or complex organizations, and how these larger patterns of behavior and organizations are structured generally plays an important role in determining which routines are exercised and which ones go unexercised. Thus a trouble-shooter type agent in one department of a business firm who has a particular set of duties as a representative of that department might well find that he or she has prior 
duties according to a set of firm routines that transcend department routines. Clearly then, analyzing the interconnections and hierarchical relationships between routines in this fashion would be a step toward a more general theory of action for business firms and other sorts of organizations. But it still seems reasonable to suppose that routines remain the building blocks for an analysis of economic agency, since whether or not a given routine is exercised does not alter the power of individuals to initiate sequences of events on the basis of that routine. That is, if individuals acting in connection with routines are plausibly described as the source of events, we may comfortably speak of the action in which organizations engage in a derivative manner, prepared to provide an analysis of how the organization structures action in terms of its assignment of responsibilities to individuals and collections of individuals through their embedding in routines.

The shorthand claim that routines can be plausibly described as eventgenerating may be reinforced by attention to what individuals involved in routines tend to believe individuates particular routines as distinct forms of activity. Note again, then, that an important dimension of routines is that the rules and procedures they involve typically possess an element of obligatoriness. Following a routine means one ought to follow certain rules and adopt certain procedures in the circumstances in which the routine applies. Putting aside whether we understand this as substantively or procedurally rational, one way of capturing the normative force routines possess is to think of routines as depending upon systems of mutually reinforcing expectations held by the individuals who participate in them. Routines may then be thought to be forms of conventional behavior in which agents act interdependently in such a manner that each recognizes rules and practices in routines have normative force. Thomas Schelling, David Lewis, and Robert Sudgen have contributed to an explanation of conventions as spontaneously emerging equilibrium solutions to coordination problems in interdependent decision-making contexts. However, we cannot follow them too closely in their game-theory formulation of conventional behavior if we want to explain agency by analyzing the social facts routines imply, since their approach assumes individuals are instrumentally rational or rational in Bayesian terms, and we have seen that this presupposes that individuals are already characterizable as independent agents. Since our a posteriori method is meant to avoid the circularity and question-begging regarding agency inherent in the neoclassical approach, our seeing the rule-governed routines as systems of mutually reinforcing expectations must allow that, though individuals may not always have the status of agents, they may nonetheless have mutually reinforcing beliefs about expected behavior. 
What, then, does treating routines as forms of conventional behavior based on mutually reinforcing expectations contribute to our understanding of agency? In a simple two-individual case, mutual expectations regarding one individual's entitlement or responsibility to act as an agent may be described as follows: individual $\mathrm{x}$ expects to do A, individual $\mathrm{y}$ expects individual $\mathrm{x}$ to do $\mathrm{A}$, individual $\mathrm{x}$ expects individual $\mathrm{y}$ to expect individual $\mathrm{x}$ to do $\mathrm{A}$, and so on potentially to higher order expectations. What we see here is that in determining entitlement or responsibility to act, expectations such as these confer agency status by recording the judgments of the individuals involved. Since our method treats social facts as widely recognized phenomena, treating routines as forms of conventional behavior based on mutually reinforcing expectations implicitly provides us with a criterion by which agents may be located and distinguished from one another. Abstracting out this location criterion, we may thus say that in the context of a given routine, an independent agent is that individual or group of individuals that expects to act as an agent, is expected by others to act as an agent, believes others have the relevant expectation, is thought to have this belief by others, and so on. ${ }^{5}$

\section{Addressing the scope of agency}

The issue of the scope of economic agency concerns the magnitude and duration of the powers that distinguishable economic agents may be represented to realistically exercise as causal agents. Here there are affinities to the philosophers' topic of personal identity, since philosophers often imagine situations in which an individual suffers an impairment in his or her power to act, and then ask whether that individual's identity is sustained. For example, an individual might lose consciousness for an extended period of time. Does this person remain himself or herself during this period? Or an individual might be transported into some unfamiliar setting in which his or her chief skills and views fail to apply. Must this individual become a new person? In economics, however, the parallel topic of agent identity necessarily approaches the magnitude and duration of agent powers from a somewhat different perspective. Recall that philosophers interested in personal identity are typically concerned with the fate of some already distinguished individual. But economists cannot presuppose who or what an economy's

${ }^{5}$ I put aside the question of what sort of regress is involved here. See Mongin and Walliser (1988) for a discussion of when infinite regressions are problematic and when not. In general, not all infinite regressions need be paradoxical. 
agents are if they intend to actually explain agency. Nor for that matter should economists follow philosophers of personal identity in supposing that economic agents (when distinguished) are likely candidates for survival through change in time and/or circumstances. Whereas philosophers hope to demonstrate personal identity is sustained through a variety of changes, or at least say under what conditions this may be the case, in economic life organizational and behavioral developments often erase the space occupied by particular routines together with the agency relations they imply. Consequently, just as we cannot presuppose that in economics we are automatically concerned with certain types of agents, for example, individuals or classes in the methodological individualist and collectivist traditions, so neither can we assume that certain types of agents automatically retain the status of being agents across different spheres of activity and through processes of change.

Explaining the magnitude and duration, or strength and permanence, of particular forms of economic agency accordingly requires that we place boundaries on distinguishable agency relations both at a point in time and also through time. At a point in time, the magnitude or strength of an agent's powers are a matter of how far-reaching the effects of an agent's actions are. For example, if in a business firm a team of individuals has responsibility for a set of cross-department activities, say, with respect to firm internal audit procedures, the influence of this teamagent's actions may in certain circumstances outweigh the actions taken by departmental agents. Conversely the scope of the latter's activities at any point in time would be partly defined by scope the team-agent's activities possessed. Regarding an agent's powers through time, that is, their duration or permanence, we need to be able to say when a given instance of agency ceases to operate, and when another emerges. Again using the business firm as a type of organization, we might in this instance look for changes that ended reliance on some routines while creating the occasion for others. Technological change affecting information storage surely would provide examples of this kind. Activities and routines made obsolete by the appearance of new ones mark off the boundaries of agency relations through time.

These remarks, however, only provide an initial outline of the dimensions involved in explicating the scope of economic agency relations, since they ignore the complexity of most real-world cause-and-effect relationships. Following J. S. Mill, contemporary philosophers of economics (Cartwright 1983, 1989; Lawson 1989; Hausman 1992; Mäki 1994) ${ }^{6}$ have

${ }^{6} \mathrm{I}$ ignore here the differences between these individuals regarding interpretation of ceteris paribus clauses. 
begun to sort out this complexity by distinguishing (i) between an agent's having a power to act in principle and that agent's actions possessing distinguishable effects in the presence or absence of overlapping and/or countervailing sources of action, and (ii) between an agent's actually exercising a capacity to act and not exercising that capacity, for whatever reason. Thus in terms of our point-in-time example above regarding the magnitude of an agent's powers, it could be found in terms of dimension (i) that a team-agent responsible for firm audit procedures has routine authority over individual departments, but that individuals within a number of departments routinely delay providing the relevant data (a case of countervailing power). Alternatively, rather than engage in delaying actions, individuals within some departments could be found to expedite firm audit routines (a case of overlapping power). Both of these cases might further be complicated along dimension (ii) were individuals in some departments able to engage in delaying actions, but did not do so (a case of an unexercised countervailing power), or were individuals in some departments able to engage in expediting actions, but did not do so (a case of unexercised overlapping power). Parallel cases concerning agency relationships through time might also be imagined.

These additional characteristics of real-world cause-and-effect relationships clearly make the analysis of the scope of agency relations more difficult, but attention to them seems only to reinforce the importance of first sorting out simple agency relationships before looking at the interrelationships between them. Ontologically, that is, investigation of the basic concepts of agent identity involving location and scope precedes investigation of their manifestations in complex cause-and-effect phenomena. This claim may seem at odds with the social facts approach taken here, since it could be argued that ordinary individuals' appraisal of routine behavior is recorded in terms of the manifestations or observed effects of agency relations rather than in terms of their originating sources. Against this, the position taken above is that ordinary individuals understand routines in terms of responsibilities to act, where having responsibility is an element of being an agent. Thus ordinary thinking regularly operates in simple ontological terms even though this more philosophical language is typically unfamiliar to most people. In contrast, what ordinary thinking is not particularly good at is moving from recognition of basic relationships of responsibility and agency to an analysis of complex agency patterns, both on account of the fact that ontological matters are rarely enunciated in ordinary thinking, and because of the inherent difficulties involved in working out representationally adequate, ontologically unified accounts of cross-cutting, multidimensional agency interrelationships. 
What the analysis here generally calls for, then, is the examination of structures of routinized behavior in various domains of economic activity within which it appears possible to distinguish decentralized responsibilities for action on the part of different sorts of economic agents. The business firm as a type of organization naturally lends itself to a variety of examples, and the method illustrated in the examples above would equally apply to the analysis of agency in the family, government, and other distinguishable domains in which routines are commonly noted. But our emphasis on routines as relatively enduring, and the relative enduringness of these traditional domains of interest, should not be thought to imply that the agency relations we may ascertain to lie behind routines by this method constitute permanent causal elements for economics as a social science. That is, in addition to the complexity we encounter in terms of multiple sources of causality, complexity also enters our analysis on account of the evolution of structures of routinized behavior. This evolution, it seems fair to say, comes about because economic agents' actions are both conditioned by the frameworks in which they operate, and simultaneously condition or bring about change in those frameworks themselves. Suppose we were to treat economic evolution as a multi-mechanism process with both selection and adaptive learning and also as a multi-level process with individuals and groups of individuals acting as agents (Vromen 1995, p. 213). Then explaining the scope and location of agency would require our considering the relative success of different types of routines empowering different types of agents in different types of environments. That evolution may well transform the forms which agency assumes, however, only demonstrates the importance of having a method for explaining its location and scope.

\section{Three concluding remarks}

(1) The discussion of agent identity here has proceeded as if one might investigate the location and individuation of agents apart from treatment of the scope of their powers as causal agents. There is modest justification for this in that the causal theory of reference adopted above allows us to communicate about things in the world without agreeing upon theories about these things. In practice, however, conventional location of responsibility to act according to systems of mutually reinforcing expectations quickly introduces scope of agency considerations into talk about who or what an economy's agents are. Being able to say where responsibility to act lies typically involves being able to say something 
about what that responsibility involves. At the same time, because action often possesses considerable unintended effects, analysis of the scope of agency goes beyond what our location criterion involves. Those party to a convention cannot anticipate all that assignment of responsibility for action implies, particularly where an agent's actions have transformative effects upon the structure of routinized behavior itself.

(2) A theme emphasized in the discussion here is that there is an important difference between the way philosophers approach the problem of personal identity and the way economists need to approach the problem of agent identity. My view is that if economists were to begin to investigate agent identity they would tend to do so along the lines of the problem of personal identity. The worst perpetrators of this misconsception are neoclassical economists who generally assume that all individuals are agents (and that households and firms, when acting as agents, are resolvable into collections of individuals). But traditional institutionalists and Marxists have made comparable mistakes by substituting their collective agents into the neoclassical equation. In both cases, normative reasoning about preferred social subjects displaces ontological reasoning about causal power and cause-and-effect relationships. Economists, however, need to examine the way the world works if they are to explain it. Indeed, policy goals regarding the well-being of different types of agents may only be promoted with an adequate understanding of the economic process.

(3) This paper began with reference to two methodological traditions in economics regarding agency: methodological individualism and methodological collectivism. The argument of this paper should have made clear that these orientations are both ontologically naïve. Their being so is in part a matter of historical forces alluded to in the remark above. No one would deny that individuals and classes have been defended as economic agents, because doing so has suited different social thinkers' world views. Nonetheless, agency as a domain of analysis is susceptible to careful examination. That it has not received it seems due in part to a failure of philosophers and methodologists of economics to focus on ontological issues. Recently, the topic of causality has begun to receive some attention (e.g. Hoover 1990). The hope this paper concludes with is that this interest will be further extended to investigation of the agents that initiate cause-and-effect sequences.

\section{References}

Becker, G. (1965) "A Theory of the Allocation of Time," Economic Journal, 65, 493-517. 


\section{Agent identity in economics}

(1976) The Economic Approach to Human Behavior, Chicago: University of Chicago Press.

Cartwright, N. (1983) How the Laws of Physics Lie, Oxford: Clarendon Press. (1989) Nature's Capacities and their Measurement, Oxford: Clarendon Press.

Davis, J. (1989) "Axiomatic General Equilibrium Theory and Referentiality," Journal of Post Keynesian Economics, 11 (3), 424-38.

(1995). "Personal Identity and Standard Economic Theory," Journal of Economic Methodology, 2 (1), 35-52.

Frege, G. (1892) "Über Sinn und Bedeutung," Zeitscrift für Philosophie und philosophische Kritik, 100, 25-50. English translation, "On Sense and Reference," Philosophical Writings, ed. P. Geach and M. Black, Oxford: Blackwell, 1952.

Gilbert, M. (1989) On Social Facts, London: Routledge.

Hausman, D. (1992) The Inexact and Separate Science of Economics, Cambridge: Cambridge University Press.

Hoover, K. (1990) “The Logic of Causal Inference,'” Economics and Philosophy, 6 (2), 207-34.

Kripke, S. (1971) "Identity and Necessity," in Identity and Individuation, ed. M. Munitz, New York: New York University Press, 135-64.

Lawson, T. (1989) "Abstraction, Tendencies and Stylised Facts: A Realist Approach to Economic Analysis," Cambridge Journal of Economics, 13, 55-78.

Mäki, U. (1992). "Friedman and Realism," Research in the History of Economic Thought and Methodology, 10, 1-36.

(1994). "Isolation, Idealization and Truth in Economics," in Idealization VI: Idealization in Economics, ed. B. Hamminga and N. De Marchi, Amsterdam and Atlanta: Rodolpi.

Mongin, P. and B. Walliser (1988) "Infinite Regressions in the Optimizing Theory of Decision," in Risk, Decision and Rationality, ed. R. Munier, Dordrecht: Reidel.

Nelson, R. and S. Winter (1982) An Evolutionary Theory of Economic Change, Cambridge, MA: Harvard University Press.

Noonan, H. (1989) Personal Identity, London: Routledge.

Parfit, Derek (1984) Reasons and Persons, Oxford: Clarendon Press.

Putnam, H. (1970) "Is Semantics Possible?", in Language, Belief, and Metaphysics, ed. H. Kiefer and M. Munitz, Albany: State University of New York Press, 50-63.

(1973) "Meaning and Reference," Journal of Philosophy, pp. 699-711.

Russell, B. (1905) "On Denoting," Mind, reprinted in Logic and Knowledge, London: Allen and Unwin, 1958.

Sugden, Robert (1991) "Rational Choice: A Survey of Contributions from Economics and Philosophy,” Economic Journal, 101 (407), 751-85.

Vromen, J. (1995) Economic Evolution. London: Routledge. 